http://jmscr.igmpublication.org/home/ ISSN (e)-2347-176x ISSN (p) 2455-0450 crossref DOI: https://dx.doi.org/10.18535/jmscr/v8i3.66

\title{
Incidental Finding of Sinus Venosus Atrial Septal Defect
}

\author{
Authors \\ Dr A.Tharun Tej ${ }^{1}$, Prof. Dr N.S.Raghupathy ${ }^{2}$ \\ ${ }^{1}$ Junior Resident, ${ }^{2} \mathrm{Head}$ of Department, Department of Pediatrics, \\ Aarupadai Veedu Medical College and Hospital, Pondicherry
}

\section{Introduction}

Sinus Venosus ASD is a rare entity consistuting $1 \%$ of all congenital heart diseases ${ }^{1} .2$ variants superior vena caval and inferior vena caval. $90 \%$ are associated with partial anomalous pulmonary venous connection [PAPVC]. Excellent prognosis if diagnosed and operated before 15 Years.

\section{Case Report}

A 5 yrs old female who presented with complaints of low grade fever, productive cough -3 days. There is no h/o breathlessness, chest pain, No h/o contact with TB patients. No history suggestive of recurrent Lower respiratory tract infections and congestive cardiac failure.

On Examination: Child is Active, Alert

- Anthropometry: Height-99cms,Weight $14.1 \mathrm{~kg}$

- Vitals: Temp-99.6 $6^{0} \mathrm{~F}$, Pulse Rate: 89beats/min, RR-28cycles/min, BP-80/60 $\mathrm{mm}$ of $\mathrm{Hg}$ in all four limbs

- No pallor/icterus/cyanosis/clubbing/ lymphadenopathy/Generalised odema

- Respiratory: Bilateral Air Entry present and normal vesicular breath sounds heard

\section{CVS Examination}

* S1, S2 heard
* wide and fixed S2 split

* 3/6 ejection systolic murmur heard only in pulmonary area

- no signs of cardiac failure

\section{Investigations}

$X$ ray hest: mild cardiomegaly with prominent PA noted

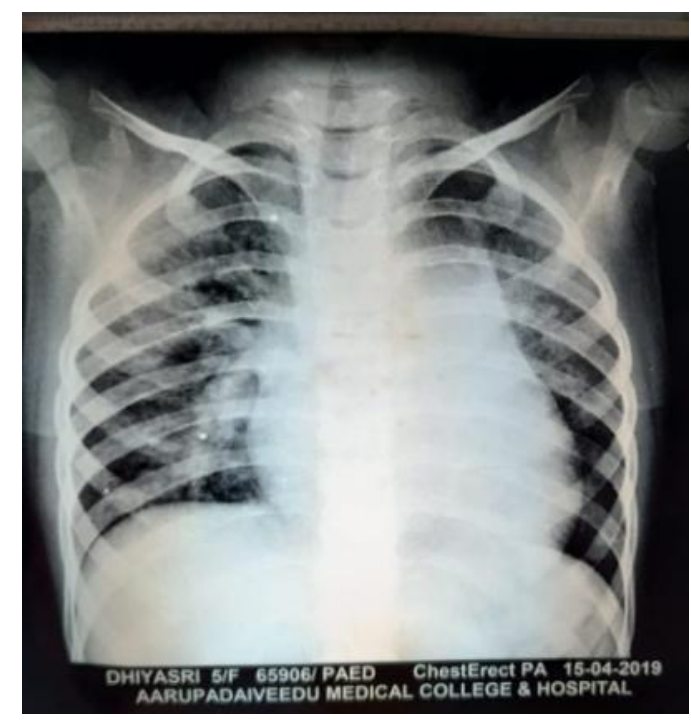

\section{Chest X ray}

\section{ECG}

\section{ECG -Showing}

1. T Wave inversion in V1-V5

2. Crochet age Sign 


\section{JMSCR Vol||08||Issue||03||Page 375-377||March}

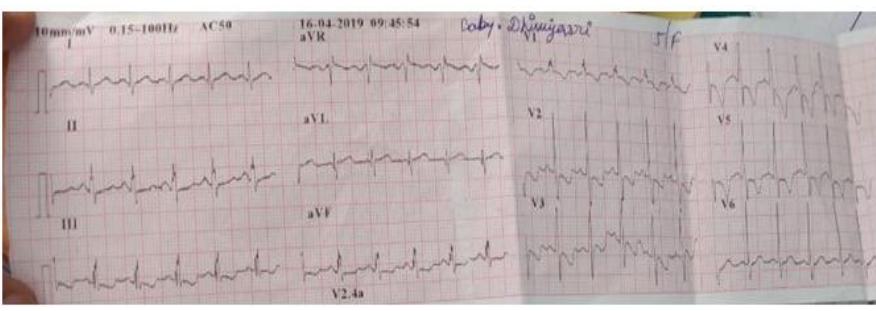

ECG

- Transesophageal 2D-ECHO:

* Large sinus venosus ASD of SVC type

* PAPVC-Right upper pulmonary veins to SVC-RA Junction, L-R shunt

* Bilateral SVC

\section{Dilated RA and RV, mil}
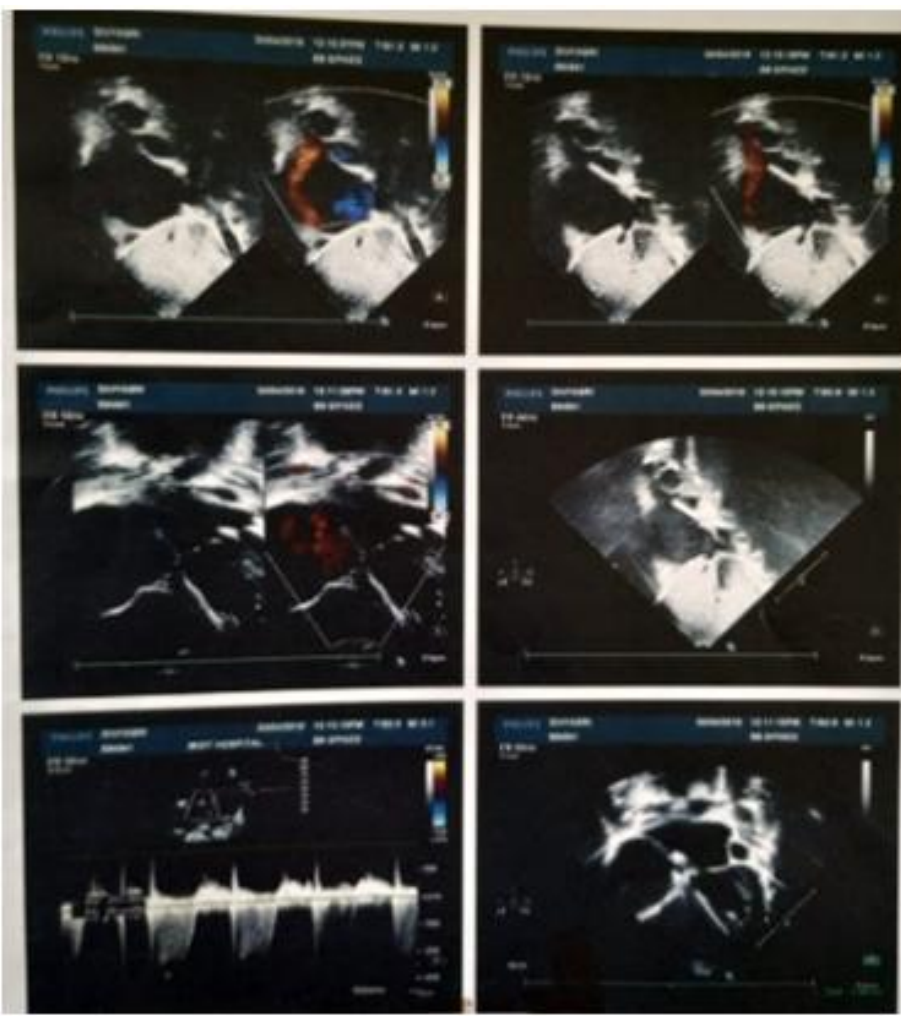

\section{Surgery}

- WARDEN procedure: closure of sinus venosus ASD and repair of PAPVC

\section{Post OP}

- Post Recovery: uneventful

- ECG: sinusrhythm, Right Axis deviation

- 2D-ECHO:no residual shunt/rerouted Right PV draining to LA without obstruction/no PAH

- Unobstructed RSVC draining into RA

- Good Biventicular function

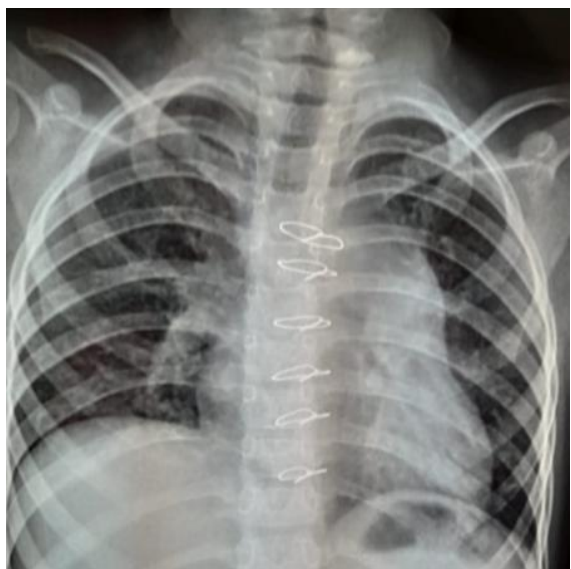

Post OP X ray Chest

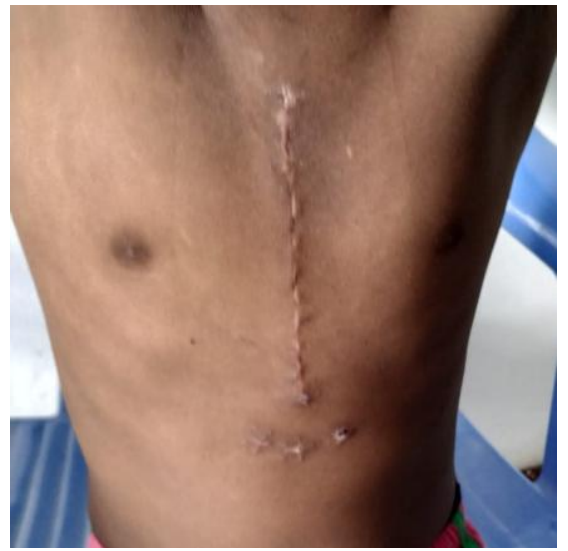

Post OP Scar

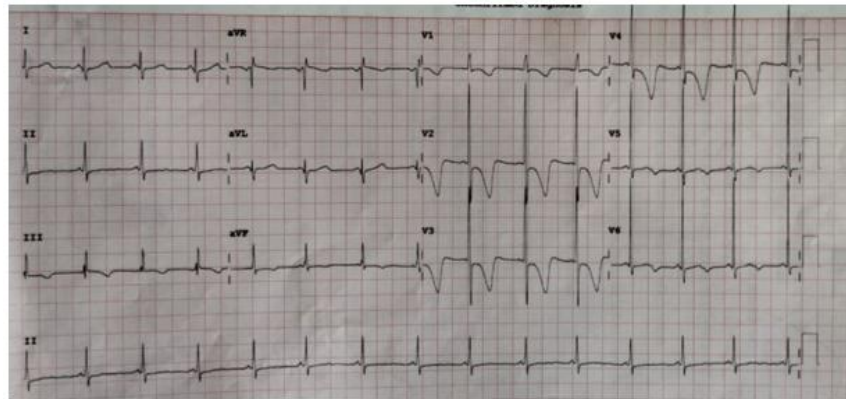

Post OP ECG

\section{Conclusion}

- Detailed systemic examination and assessment of all patients aid in early diagnosis and management of children with sinus venosus ASD

- Excellent prognosis post op if operated before 15years

- so high index of suspicion is required to diagnose sinus venosus ASD. 


\section{References}

1. Alpendurada F, Wage R, Mohiaddin R. Evaluation of a sinus venosus atrial septal defect by magnetic resonance: a case report. Rev Port Cardiol. 2008 Oct. 27(10):1317-21.

2. Warden HE, Gustafson RA, Tarnay TJ, Neal WA. An alternative method for repair of partial anomalous pulmonary venous connection to the superior vena cava. Ann Thorac Surg. 1984 Dec. 38(6):601-5.

3. Chen CA, Wang JK, Hsu JY, Hsu HH, Chen SJ, Wu MH. Diagnosis of inferior sinus venosus atrial septal defects using transthoracic three-dimensional echocardiography. J Am Soc Echocardiogr. 2010 Apr. 23(4):457.e4-6.

4. Murphy JG, Gersh BJ, McGoon MD, et al. Long-term outcome after surgical repair of isolated atrial septal defect. Follow-up at 27 to 32 years. N Engl J Med. 1990 Dec 13. 323(24):1645-50.

5. Radzik D, Davignon A, van Doesburg N, et al. Predictive factors for spontaneous closure of atrial septal defects diagnosed in the first 3 months of life. J Am Coll Cardiol. 1993 Sep. 22(3):851-3. 